\title{
RECURSOS TECNOLÓGICOS EM MUSEUS DE CIÊNCIAS: Tendências em Estudos Brasileiros
}

\author{
Pedro Miguel Marques da Costa ${ }^{1}$ \\ Marcelo Rocha ${ }^{2}$
}

\begin{abstract}
RESUMO
Os recursos tecnológicos estão cada vez mais presentes no cotidiano das pessoas e nas mais diversas situações, por exemplo nos museus de ciências. Com o objetivo de investigar se a tecnologia vem sendo utilizada em museus, analisou-se a produção acadêmica a partir de artigos publicados em revistas de Qualis A1 na área de ensino, no período de 2015 a 2019. Foram analisadas 13 revistas e identificados 23 artigos com base nos descritores museus, tecnologia e tecnologia em museus. Posteriormente, estes artigos foram agrupados por categorias à luz da análise de conteúdo. Os resultados evidenciaram um decréscimo de publicações sobre museus e um discreto, mas não significativo, aumento de publicações na área da tecnologia. Acerca do uso da tecnologia em museus não foi encontrada nenhuma publicação. Assim, o presente estudo traz importantes desdobramentos no sentido de sinalizar a carência de trabalhos que investigam como a tecnologia tem sido incorporada em museus, posto que se trata de um tema atual e de grande impacto social.
\end{abstract}

Palavras-chave: Espaços educativos não formais. Museus. Tecnologia.

\section{TECHNOLOGICAL RESOURCES IN SCIENCE MUSEUMS: TRENDS IN BRAZILIAN STUDIES}

\section{ABSTRACT}

Technological resources are increasingly present in people's daily lives and in the most diverse situations, such as in science museums. In order to investigate whether the technology has been used in museums, academic production was analyzed from articles published in Qualis A1 magazines, in the teaching area, in the period from 2015 to 2019.13 magazines were analyzed and 23 were identified articles based on the descriptors: museums, technology and technology in museums. Subsequently, these articles were grouped by categories in the light of content analysis. The results showed a decrease in publications about museums and a discreet, but not significant, increase in publications in the area of technology. No publication was found regarding the use of technology in museums. Thus, the present study brings important developments in the sense of signaling the lack of work that investigates how technology has been incorporated into museums, since it is a current topic and of great social impact.

Keywords: Non-formal educational spaces. Museums. Technology.

Recebido em: 6/6/2020

Aceito em: $7 / 7 / 2020$

\footnotetext{
1 Autor correspondente. Centro Federal de Educação Tecnológica Celso Suckow da Fonseca - Cefet/RJ. R. Gen. Canabarro, 485 - Maracanã, Rio de Janeiro/RJ, Brasil. CEP 20271-204. http://lattes.cnpq.br/7496443490400028. https://orcid.org/0000-0001-8839-2878. pedro_ mmco@hotmail.com

2 Centro Federal de Educação Tecnológica Celso Suckow da Fonseca - Cefet/RJ. http://lattes.cnpq.br/5640018108479090. https://orcid. org/0000-0003-4472-7423.
} 
Muitas definições são possíveis para o espaço não formal. Na área da educação, o termo tem sido utilizado pelos profissionais e pesquisadores para descrever os ambientes diferentes da escola, onde se podem desenvolver atividades educativas. Já o espaço formal é entendido como um local onde a educação é realizada de maneira formalizada, garantida por aparatos legais e organizada segundo uma padronização nacional (JACOBUCCI, 2008). Na tentativa de estabelecer uma definição para espaço não formal, Jacobucci (2008) sugere duas categorias. Uma categoria diz respeito a locais institucionalizados, regulamentados e com uma equipe técnica responsável pelas atividades executadas. Dentro desse conjunto, encontram-se os museus, centros de ciência, parques ecológicos, zoológicos, planetários, aquários, entre outros. A segunda categoria engloba locais que não são instituições, mas nas quais é possível adotar práticas educativas, como teatro, parques, praia, rua, cinema, entre outros espaços.

Marandino (2017) apresenta a definição de educação não formal como qualquer atividade organizada fora do sistema formal de educação, operando separadamente ou como parte de uma atividade mais ampla, que pretende servir a clientes previamente identificados como aprendizes e que possuem objetivos de aprendizagem. Assim, a educação não formal pode ser considerada um elemento essencial na composição das redes cotidianas de conhecimento, e caracteriza-se, de modo geral, por atividades coletivas e de participação voluntária, com conteúdos flexíveis, ao contrário do que é preconizado na educação formal (GOUVÊA et al., 2010). Embora ambas as modalidades de educação (formal e não formal) tenham objetivos similares, a educação não formal possui particularidades em razão da forma e do espaço em que suas práticas se realizam (CASCAIS; GHEDIN; TERÁN, 2014).

Nesse sentido, Pivelli (2006) considera que os processos metodológicos realizados na educação não formal estão menos expressos pela escrita e mais codificados na fala, e as ações interativas são fundamentais para a aquisição de saberes, o que a caracteriza como uma ação coletiva. Torna-se necessário, no entanto, compreender que as atividades educativas realizadas nos espaços não formais institucionalizados possuem características diferentes das feitas na escola, o que reforça o papel da complementaridade desses espaços.

Dentre os processos metodológicos que acontecem tanto em espaços formais quanto não formais, destacam-se as ações de divulgação científica. Albagli (1996) faz comparações sobre a efetividade destas ações em métodos formais e não formais. Ao mesmo tempo em que atividades não formais de divulgação científica poderiam atuar no sentido de consolidar ou atualizar a educação científica realizada em ambientes formais de ensino, outros estudos indicam que não é possível à escola atribuir toda a educação e informação científica necessária ao cidadão, posto que as transformações técnico-científicas são rápidas e ocorrem a todo o momento.

Nesta discussão, Falk e Needham (2011) destacam que o conhecimento das ciências não pode ser visto como instantâneo, e defendem que é algo a ser desenvolvido por meio da acumulação de experiências, que podem ocorrer numa variedade de instituições e não apenas nas de educação formal. A complementaridade entre espaços formais e não formais de educação, portanto, faz-se necessária, considerando também a contribuição da divulgação da ciência como ferramenta para potencializar a educação e a cultura científica. 
Mesmo diante da importância de entendermos a necessidade da complementaridade entre espaços formais e não formais, ainda se percebe que alguns educadores, por desconhecerem as características e importância dos espaços não formais da sua região, não aproveitam totalmente seu potencial educativo, acabando, assim, por perder a oportunidade de alcançar uma educação científica que possibilite transformar uma visita escolar em um momento de aprendizagem e troca de experiências (QUEIROZ et al., 2011). Entre os espaços não formais que se dedicam quase integralmente à divulgação científica, podemos destacar os museus e centros de ciência (LOUREIRO, 2003). O caráter educativo dessas instituições é evidenciado pela sua aproximação com o ensino formal, principalmente com o ensino de ciências (JACOBUCCI, 2008).

Loureiro (2003) destaca que, embora haja uma tendência em fazer referências aos museus e centros de ciência como fenômeno único, existe uma certa diferenciação entre esses dois espaços. Para este autor, o museu de ciências configura-se como uma instituição voltada à preservação, gestão e difusão da história, produtos e influências socioculturais da ciência, sendo suas exposições a prática essencial e determinante como instrumento de divulgação científica. Para Queiroz et al. (2011), o museu é considerado um dos espaços não formais institucionalizados que possui a função de expor materiais históricos antigos e raros, destinados ao estudo e à contemplação. Já os centros de ciência surgiram nos Estados Unidos, no período da guerra fria, com o objetivo de difundir a ciência e seus produtos por meio de exposições interativas, mas, ao contrário do museu, "encontram-se ausentes de tais instituições os objetos pertencentes ao passado científico e o caráter histórico e sociocultural do desenvolvimento da ciência e da tecnologia" (LOUREIRO, 2003, p. 89).

Packer (2008) defende que o papel social dos museus se situa para além do seu valor educativo. Em seu estudo, foi possível perceber que os momentos vivenciados em museus proporcionaram benefícios para o bem-estar dos visitantes a ponto de levarem para o cotidiano as experiências apreendidas durante a visita. $O$ autor ressalta que, dentre estes benefícios, destacam-se os aspectos psicológicos, como o relaxamento, a tranquilidade e a reflexão.

Assim, para além da dimensão educativa, Chelini e Lopes (2008) afirmam que os museus se configuram como espaços de lazer, informação e inclusão social. Consideram ainda, que as exposições são fundamentais na relação dos museus com a sociedade.

Neste sentido, as exposições científicas possuem um importante papel na veiculação de informações ao público. A apresentação de um conjunto de objetos ao público, porém, não é suficiente para torná-los compreensíveis, assim como o sentido dado a eles não é diretamente proporcional à quantidade de textos que acompanham os objetos (CHELINI; LOPES, 2008). Em Davallon (1989 apud CHELINI; Lopes, 2008), o sentido emerge da natureza semiótica de exposições, que deve ser o centro de interesse desses espaços, uma vez que visam a que o público faça descobertas, adquira conhecimentos e, possivelmente, forme uma opinião sobre um determinado assunto. Gouvêa et al. (2010) defendem que o museu deve proporcionar a interpretação da sua narrativa pelo visitante, e que, por maior que a tentativa dos idealizadores seja articular os conhecimentos científicos nas exposições, o visitante apropria-se de maneira autônoma, variável e livre.

Dado que um dos objetivos das exposições científicas é estabelecer a aproximação entre o conhecimento científico e o visitante, o desafio é, portanto, assegurar que aconteça uma comunicação efetiva entre eles. 
Torna-se, então, importante saber como os indivíduos se apropriam dos temas veiculados pelos museus e como isso pode implicar mudanças de atitudes, valores, condutas, etc. Para que os museus, particularmente os de ciência, possam estabelecer um vínculo autêntico com seu público real e potencial é preciso que ofereçam experiências valiosas (VALENTE; CAZELLI; ALVES, 2005, p. 201).

Atento a esta necessidade, Bassoli (2013) afirma que os espaços não formais acabam por propor estratégias no sentido de melhorar o processo de comunicação, rompendo com os modelos tradicionais de conhecimento. Uma das formas de comunicação é a mediação, elemento fundamental em museus e centros de ciência, posto que proporciona interatividade nesses espaços. Nesse sentido, destaca-se o papel dos mediadores para que os objetivos das exposições sejam alcançados (OLIVEIRA; SILVA, 2011).

Bassoli (2013) salienta que é necessário investir nesses atores para efetivar uma difusão dos conhecimentos e para que a ciência esteja ao alcance de todos. Por outro lado, Marandino (2011) ressalta que os museus não são escolas e mediadores não são professores. Nesse sentido, a autora assevera que o papel da mediação deve ser dimensionado, pois os mediadores não são imprescindíveis e as exposições não podem depender deles para serem compreendidas. Ela acredita, no entanto, que é possível que a mediação humana seja a melhor forma de obter uma maior aprendizagem dos conceitos abordados nas exposições, e que os objetivos destas devem definir as formas de mediação com o público.

Pensando nestes processos de mediação e interação que se estabelecem nos museus e centros de ciências, é importante situar o papel que a tecnologia assume neste novo cenário que se configura. Assim, dado o avanço tecnológico e os hábitos dos visitantes, surge a necessidade de inovar, incorporando novos recursos que despertem o interesse do público pelos espaços não formais de educação. Entendendo que o termo tecnologia é polissêmico e bastante amplo, trazemos Veraszto et al. (2008), que o consideraram um conjunto de conhecimentos que vai além de servir como uma simples aplicação de conceitos e teorias científicas ou do manejo e reconhecimento de modernos artefatos. Para estes autores, há ainda que considerar a concepção da tecnologia em razão de novas demandas e exigências sociais, o que acaba por modificar todo um conjunto de valores e, por fim, agrega-se à cultura. De modo geral, a tecnologia abrange não apenas os produtos artificiais fabricados pelo ser humano, mas também os processos de produção que envolvem máquinas e recursos necessários em um sistema sociotécnico de fabricação.

A tecnologia é definida, segundo Gilbert (1995) e Veraszto et al. (2003), como a determinação e a descrição de uma necessidade; a formulação e seleção de ideias; a criação e prova de um produto; a fabricação do artificial; a aceitação da complexidade da necessidade e a tecnologia como objeto particular. Usando a definição de tecnologia segundo estes autores, a consideramos, no presente estudo, o uso de qualquer recurso interativo, ferramentas ou materiais alternativos, no sentido de adequar um espaço de acordo com a sociedade atual.

Diante do exposto, entendemos que a tecnologia pode permitir um novo modo de fazer educação tanto nos espaços formais quanto não formais, uma vez que "proporciona um novo modo de se comunicar implicando a organização de uma sociedade em rede, conectada em diferentes espaços que desafiam o ensinar e aprender propostos 
pela escola tradicional" (MACHADO; SILVA; CATAPAN, 2014, p. 67). Levantamos, entretanto, o seguinte questionamento: Os museus de ciências têm incorporado os recursos tecnológicos em suas práticas?

No sentido de aprofundar a discussão até aqui apresentada e responder à pergunta de pesquisa, o presente estudo teve como objetivo investigar se existem produções acadêmicas voltadas para o entendimento de como e se a tecnologia vem sendo utilizada em espaços não formais, especificamente em museus de ciências.

\section{METODOLOGIA}

A abordagem metodológica utilizada nesta pesquisa foi do tipo levantamento bibliográfico, que, para Galvão (2017, p. 1), é:

Se potencializar intelectualmente com o conhecimento coletivo, para se ir além. É munir-se com condições cognitivas melhores, a fim de: evitar a duplicação de pesquisas, ou quando for de interesse, reaproveitar e replicar pesquisas em diferentes escalas e contextos; observar possíveis falhas nos estudos realizados; conhecer os recursos necessários para a construção de um estudo com características específicas; desenvolver estudos que cubram lacunas na literatura trazendo real contribuição para a área de conhecimento; propor temas, problemas, hipóteses e metodologias inovadoras de pesquisa; otimizar recursos disponíveis em prol da sociedade, do campo científico, das instituições e dos governos que subsidiam a ciência.

Realizar um levantamento bibliográfico possibilita, portanto, quantificar a produção científica na área, concentrando-a em um único lugar para outros estudiosos que buscarem os mesmos fins (SILVA et al., 2017).

Inicialmente foi feito o levantamento, na plataforma Sucupira, das revistas de Qualis A1, em língua portuguesa, na área de ensino. Foi encontrado um total de 33 revistas. Em seguida, foram consideradas apenas as revistas da área de ensino de Ciências, Biologia, Química e Física, passando para 13 o número de revistas a analisar. O levantamento foi realizado nestas 13 revistas (Quadro 1), 12 das quais são brasileiras e uma é portuguesa, no período de 2015 a 2019. Neste período estas revistas publicaram um total de 3.696 artigos.

Quadro 1 - Revistas analisadas

\begin{tabular}{|l|l|}
\hline País de Publicação & \multicolumn{1}{|c|}{ Revista } \\
\hline \multirow{4}{*}{ Brasil } & Ciência \& Educação \\
\cline { 2 - 2 } & Educação \& Sociedade \\
\cline { 2 - 2 } & Educação e Pesquisa \\
\cline { 2 - 2 } & Educação e Realidade \\
\cline { 2 - 2 } & Educação em Revista (UFMG - on-line) \\
\cline { 2 - 2 } & Educação em Revista (Unesp - Marília) \\
\hline & Educar em Revista \\
\hline & Ensaio: Pesquisa em Educação em Ciências (on-line) \\
\cline { 2 - 3 } & Pró-Posições (Unicamp on-line) \\
\cline { 2 - 2 } & Revista Brasileira de Educação \\
\cline { 2 - 2 } & Revista Brasileira de Ensino de Física (on-line) \\
\cline { 2 - 2 } & Revista Brasileira de Estudos Pedagógicos (RBEP-Inep) \\
\hline Portugal & Revista Lusófona de Educação \\
\hline
\end{tabular}

Fonte: Os autores (2020). 
Como descritores foram usados os termos museu, tecnologia e tecnologia em museus, presentes nos títulos das publicações. A partir desta busca foram encontrados 56 artigos. Considerando o foco desta pesquisa, que é entender como a tecnologia tem sido incorporada nas práticas de museus de ciências, foram considerados os artigos que tratavam do uso do museu como um espaço educativo não formal e o emprego de algum tipo de tecnologia em sala de aula, uma vez que não se encontrou nenhum artigo sobre o uso da tecnologia em museus. Assim, foram lidos os resumos e metodologia dos 56 artigos, dos quais apenas 23 corresponderam aos critérios que atendiam ao objetivo da pesquisa.

Para além das palavras-chave, público-alvo, da relação da produção e distribuição de acordo com a região geográfica e instituição de origem, foram criadas categorias à luz da análise de conteúdo (BARDIN, 2011), tanto para as publicações sobre museus quanto para as publicações sobre tecnologia. A análise de conteúdo pode ser definida como um conjunto de instrumentos metodológicos em constante aperfeiçoamento, que se presta a analisar diferentes fontes de conteúdos verbais e não verbais. Segundo Freitas, Cunha e Moscarola (1997), trata-se de uma técnica refinada, que exige do investigador disciplina, dedicação, paciência e tempo, fazendo-se necessário, também, um certo grau de intuição, imaginação e criatividade, sobretudo na definição das categorias de análise, não esquecendo o rigor e a ética, que são fatores essenciais.

\section{ANÁLISE E DISCUSSÃO DOS RESULTADOS}

Dos 23 artigos encontrados, 14 foram relativos a museus, identificados no estudo de $\mathrm{M} 1$ a M14, e 9 relativos à tecnologia, identificados de T1 a T9. Relativamente aos artigos sobre museus, verificou-se um decréscimo do número de publicações, ao longo dos anos. Cinco dos artigos foram publicados em 2015, quatro em 2016, dois em 2017 e 2018 e apenas um artigo foi publicado em 2019. Quanto aos artigos sobre tecnologia, o maior número de publicações foi registrado em 2019, com três artigos, e, tanto em 2015 quanto em 2016 e 2018, foram publicados dois artigos, verificando-se, nesta área, um discreto aumento no ano de 2019.

No que diz respeito à distribuição de acordo com a região geográfica e instituição de origem, verificou-se que o maior número de publicações sobre museus ocorreu no Estado do Rio de Janeiro (Quadro 2), destacando-se as instituições Universidade Federal do Estado do Rio de Janeiro (Unirio) e a Fundação Oswaldo Cruz (FioCruz), e o maior número de publicações sobre tecnologia ocorreu no Estado do Rio Grande do Sul. Uma vez que vários artigos foram escritos em pareceria com vários Estados e/ou países, o número total de instituições é superior ao número total de publicações. Destacam-se vários artigos publicados em parceria entre instituições brasileiras e instituições internacionais sediadas em Portugal, Itália, Estados Unidos da América e Colômbia. 
Quadro 2 - Distribuição de acordo com a região geográfica e instituição de origem

\begin{tabular}{|c|c|c|c|c|}
\hline Estado/País & $\begin{array}{c}\text { Museus } \\
\text { (Número de } \\
\text { artigos) }\end{array}$ & $\begin{array}{l}\text { Instituição de Publicação } \\
\text { (Museus) }\end{array}$ & $\begin{array}{l}\text { Tecnologia } \\
\text { (Número de } \\
\text { artigos) }\end{array}$ & $\begin{array}{l}\text { Instituição de } \\
\text { Publicação } \\
\text { (Tecnologia) }\end{array}$ \\
\hline Goiás & - & - & 1 & $\begin{array}{c}\text { Universidade Federal de } \\
\text { Goiás }\end{array}$ \\
\hline Maranhão & 1 & $\begin{array}{c}\text { Universidade Federal do } \\
\text { Maranhão }\end{array}$ & - & - \\
\hline Minas Gerais & 1 & $\begin{array}{c}\text { Universidade Federal do } \\
\text { Triângulo Mineiro }\end{array}$ & - & - \\
\hline Pará & 1 & $\begin{array}{c}\text { Universidade Federal do } \\
\text { Pará }\end{array}$ & - & - \\
\hline Paraná & 1 & $\begin{array}{l}\text { Universidade Federal do } \\
\text { Paraná }\end{array}$ & 2 & $\begin{array}{c}\text { Universidade Estadual } \\
\text { de Ponta Grossa - } 1 \\
\text { Faculdade Inspirar, } \\
\text { Curitiba - } 1\end{array}$ \\
\hline Piauí & 1 & $\begin{array}{l}\text { Universidade Federal do } \\
\text { Piauí }\end{array}$ & - & - \\
\hline Rio de Janeiro & 5 & $\begin{array}{c}\text { Universidade Federal do } \\
\text { Estado do Rio de Janeiro } \\
-2 \\
\text { Universidade Federal do } \\
\text { Rio de Janeiro - } 1 \\
\text { Fundação Oswaldo Cruz } \\
-2 \\
\text { Pontifícia Universidade } \\
\text { Católica do Rio de Janeiro } \\
-1\end{array}$ & 1 & Unilasalle Rio de Janeiro \\
\hline $\begin{array}{l}\text { Rio Grande do } \\
\text { Sul }\end{array}$ & - & - & 3 & $\begin{array}{c}\text { Universidade Regional } \\
\text { Integrada do Alto } \\
\text { Uruguai e das Missões } \\
-1 \\
\text { Universidade Federal do } \\
\text { Rio Grande do Sul - } 1 \\
\text { Pontifícia Universidade } \\
\text { Católica do Rio Grande } \\
\text { do Sul - } 1\end{array}$ \\
\hline São Paulo & 2 & $\begin{array}{c}\text { Universidade de São } \\
\text { Paulo - } 2 \\
\text { Universidade Federal do } \\
\text { ABC - } 1 \\
\text { Universidade Anhembi } \\
\text { Morumbi }-1\end{array}$ & 1 & $\begin{array}{l}\text { Universidade de São } \\
\text { Paulo }\end{array}$ \\
\hline Tocantins & 1 & $\begin{array}{c}\text { Universidade Federal do } \\
\text { Tocantins }\end{array}$ & - & - \\
\hline Colômbia & 1 & University Maloka & - & - \\
\hline $\begin{array}{l}\text { Estados Unidos } \\
\text { da América }\end{array}$ & 1 & $\begin{array}{c}\text { College of Education } \\
\text { Oregon State University }\end{array}$ & - & - \\
\hline Itália & 1 & University of Milano & - & - \\
\hline Portugal & - & - & 2 & $\begin{array}{c}\text { Instituto de Educação, } \\
\text { Universidade de Lisboa } \\
-1 \\
\text { Universidade do Minho } \\
-1\end{array}$ \\
\hline
\end{tabular}

Fonte: Os autores (2020). 
Analisando os participantes envolvidos nos trabalhos analisados, no caso dos museus destacam-se os alunos da educação básica (M5 e M12), do Ensino Superior (M8 e M11) e estudos com público visitante de forma espontânea (M1 e M3); um dos estudos envolveu os alunos da educação básica e do Ensino Superior (M2); outro os professores e alunos do Ensino Superior do curso de Física (M13); e outro envolveu os alunos da educação básica, professores, mediadores e funcionários do museu (M7); o restante dos trabalhos foram de revisão de literatura (M6, M10 e M14). Na área da tecnologia destacam-se os alunos do Ensino Superior (T3 e T9), dos cursos de Matemática e Radiologia, respectivamente; alunos da educação básica (T2); docentes universitários (T5); gestores escolares e coordenadores (T7); o restante dos trabalhos foram de revisão de literatura (T1, T4, T6 e T8).

Em relação às palavras-chave mais citadas, destacam-se as palavras museu e educação (Quadro 3), assim como aprendizagem/atividades de aprendizagem (Quadro 4).

Quadro 3 - Palavras-chave mais citadas nos trabalhos sobre museus

\begin{tabular}{|c|c|}
\hline Palavra-chave & Número de Artigos \\
\hline Museu/Museus & 7 \\
\hline Educação & 4 \\
\hline Museu de Ciências & 3 \\
\hline Divulgação Científica & 3 \\
\hline Educação não formal & 3 \\
\hline
\end{tabular}

Fonte: Os autores (2020).

Quadro 4 - Palavras-chave mais citadas nos trabalhos sobre tecnologia

\begin{tabular}{|l|c|}
\hline \multicolumn{1}{|c|}{ Palavra-chave } & Número de Artigos \\
\hline Aprendizagem/Atividades de aprendizagem & 3 \\
\hline TIC & 2 \\
\hline Tecnologia digital & 2 \\
\hline Educação & 2 \\
\hline Tecnologias & 2 \\
\hline Tecnologias educacionais/educativas & 2 \\
\hline
\end{tabular}

Fonte: Os autores (2020).

Para os trabalhos sobre museus foram criadas sete categorias (Quadro 5), e para os trabalhos sobre tecnologia quatro categorias (Quadro 6).

Quadro 5 - Categorias e objetivos dos trabalhos analisados sobre museus

\begin{tabular}{|l|c|l|}
\hline \multicolumn{1}{|c|}{ Categoria } & Artigo(s) & \multicolumn{1}{c|}{ Objetivo(s) } \\
\hline $\begin{array}{l}\text { Levantamento } \\
\text { do perfil dos } \\
\text { visitantes }\end{array}$ & M1 e M2 & $\begin{array}{l}\text { Investigar como ocorre o ensino nos museus e sua contribuição } \\
\text { para a divulgação científica em virtude da sua grande popularidade } \\
\text { e seu papel social, cultural e científico. }\end{array}$ \\
\hline Teatro no museu & $\mathrm{M} 3$ & $\begin{array}{l}\text { Analisar como atividades teatrais oferecidas nos museus são usadas } \\
\text { como estratégia de educação e divulgação da ciência. }\end{array}$ \\
\hline
\end{tabular}




\begin{tabular}{|l|c|l|}
\hline $\begin{array}{l}\text { História da } \\
\text { educação em } \\
\text { museus de } \\
\text { ciências }\end{array}$ & M4 e M13 & $\begin{array}{l}\text { Realizar um diálogo entre o pensamento de um filósofo e o } \\
\text { educador, tendo em conta os estudos sobre a educação em museus } \\
\text { e centros de ciências. } \\
\text { Colaborar com o aumento da qualidade da educação científica na } \\
\text { região, atuando em parceria com a comunidade. }\end{array}$ \\
\hline $\begin{array}{l}\text { Visita escolar ao } \\
\text { museu }\end{array}$ & $\begin{array}{l}\text { M5, M7, M8, } \\
\text { M12 e M13 }\end{array}$ & $\begin{array}{l}\text { Refletir acerca dos espaços museológicos como prática educativa. } \\
\text { Compreender a experiência de adolescentes em museus de } \\
\text { ciências em visita fora do contexto escolar. }\end{array}$ \\
\hline $\begin{array}{l}\text { Formação em } \\
\text { museus }\end{array}$ & M11 & $\begin{array}{l}\text { Analisar a formação de mediadores em museus de ciências a partir } \\
\text { da compreensão dos saberes mobilizados nesse processo. }\end{array}$ \\
\hline $\begin{array}{l}\text { Criação de museu } \\
\text { digital }\end{array}$ & M9 & $\begin{array}{l}\text { Criar um museu digital, acompanhar a sua aplicação prática, } \\
\text { perceber como esse equipamento cultural de natureza virtual pode } \\
\text { potencializar e apresentar um acervo de informações, imagens e } \\
\text { sons de um território que é um museu a céu aberto, que pode } \\
\text { ser visitado por meio de realidade virtual e suscitar o desejo de } \\
\text { conhecer o território e seus patrimônios cultural e natural in loco. }\end{array}$ \\
\hline $\begin{array}{l}\text { Revisão de } \\
\text { literatura }\end{array}$ & M6, M10 e & $\begin{array}{l}\text { Apresentar a importância da formação de professores realizada } \\
\text { nos museus, quando o contato com as obras presentes é elemento } \\
\text { de desenvolvimento da profissionalidade. } \\
\text { Identificar e descrever características e tendências das pesquisas } \\
\text { desenvolvidas no subcampo educação em museus de ciências. }\end{array}$ \\
\hline
\end{tabular}

Fonte: Os autores (2020).

Como pode-se verificar, dos trabalhos analisados a maior parte diz respeito a visitas escolares realizadas por alunos da educação básica e Ensino Superior, com o objetivo de refletir acerca dos museus como espaços educativos e compreender a experiência dos alunos nestes espaços fora do contexto escolar. Das demais atividades, destacam-se a realização de peças teatrais nos museus como estratégia de educação e divulgação da ciência, assim como da formação de mediadores realizada em museus.

Quadro 6 - Categorias e objetivos dos trabalhos analisados sobre tecnologia

\begin{tabular}{|l|c|l|}
\hline \multicolumn{1}{|c|}{ Categoria } & Artigo(s) & \multicolumn{1}{c|}{ Objetivo(s) } \\
\hline $\begin{array}{l}\text { Criação de biblioteca } \\
\text { virtual }\end{array}$ & T2 & $\begin{array}{l}\text { Investigar como os estudantes interpretam e manipulam as } \\
\text { informações acessadas via web. }\end{array}$ \\
\hline $\begin{array}{l}\text { Uso de Tecnologias } \\
\text { Digitais (objetos } \\
\text { virtuais e softwares) }\end{array}$ & T3 e T5 & $\begin{array}{l}\text { Investigar o processo de construção de conceitos por } \\
\text { estudantes que fizeram o uso das tecnologias digitais. } \\
\text { Compreender as competências evidenciadas pelos docentes } \\
\text { que empreendem boas práticas pedagógicas com Tecnologias } \\
\text { Digitais. }\end{array}$ \\
\hline Questionários on-line & T7 e T9 & $\begin{array}{l}\text { Promovero uso das Tecnologias da Informação e Comunicação } \\
\text { (TICs) nas escolas públicas estaduais. } \\
\text { Utilizar ferramentas e métodos inovadores e tecnológicos } \\
\text { associados a conceitos teóricos. }\end{array}$ \\
\hline $\begin{array}{l}\text { Revisão de literatura/ } \\
\text { mapeamento }\end{array}$ & T1, T4, T6 e & $\begin{array}{l}\text { Investigar o papel das Tecnologias da Informação e da } \\
\text { Comunicação (TICs) na promoção da discussão e da ação } \\
\text { sociopolítica sobre controvérsias sociocientíficas em contexto } \\
\text { escolar, com o intuito de visar, sobretudo, o desenvolvimento } \\
\text { do cidadão nas suas diferentes dimensões, tendo em vista } \\
\text { uma participação ativa e fundamentada na sociedade e na } \\
\text { resolução de seus problemas. }\end{array}$ \\
\hline
\end{tabular}

Fonte: Os autores (2020). 
No que diz respeito aos trabalhos sobre tecnologia, destaca-se a preocupação dos docentes em inserir, nas suas práticas pedagógicas, recursos tecnológicos, desde os mais simples, como os questionários on-line, para promover o uso das tecnologias de informação e comunicação, até o uso de objetos virtuais e softwares, utilizando este tipo de recursos aliados a métodos inovadores e tecnológicos associados a conceitos teóricos de disciplinas, como a Física e a Química, por exemplo. Além disso, foi possível perceber a presença de trabalhos de revisão de literatura com o objetivo de investigar o papel e a importância das Tecnologias de Informação e Comunicação no contexto escolar, destacando vantagens e desvantagens.

Como pode-se observar nesta pesquisa, os museus atendem a um público bastante abrangente, devendo ser cada vez mais usado como espaço educativo e também como espaço de formação, corroborando os estudos de Costa e Wazenkeski (2015), ao afirmarem que os museus devem ser locais sem restrição de público, onde a visita pode e deve ser um momento de prazer, aventura e aprendizado. Estes autores destacam que, quando um grupo de alunos visita um museu, a ideia principal não deve ser "ensinar", mas fazer com que as informações sejam passadas de forma simples, lúdica e que os alunos aprendam com diversão. O mesmo deve acontecer com os professores que, antes da visita ao museu, devem viabilizar a relação das atividades propostas com a escola, tomando o museu como instrumento de troca dialógica de conhecimento, de reflexão crítica da história e ação prática. Desta maneira, alunos e professores constroem, individualmente e em grupo, uma relação com aquilo que se está dialogando e com os temas de interesse para um melhor aprendizado, adquirindo uma maior e melhor comunicação com o museu.

Nesse sentido, Falk e Needham (2011) fazem uma reflexão interessante sobre a cultura em que estamos inseridos, que valoriza muito a aquisição de novos conhecimentos, ou seja, deve-se tentar sempre aprender coisas diferentes em detrimento da valorização de experiências que possam fortalecer e aprofundar os conhecimentos que já se tem. Sob este olhar, os espaços não formais de educação, como os centros de ciência e museus, possuem um papel importante.

A elaboração de atividades educativas em espaços não formais, para o educador, constitui uma possibilidade para ampliar a sua maneira de atuar, ao diversificar metodologias que possibilitam a abordagem de temas de interesse social, contextualizados e interdisciplinares, que contribuam para a formação da cidadania (MARCONSIN; OLIVEIRA; RIBEIRO, 2013). Assim, aqueles envolvidos com a educação devem considerar e olhar esses espaços como propícios à aprendizagem e à contextualização dos conteúdos científicos e culturais.

Os estudos de Oliveira e Silva (2008) evidenciaram que os museus possuem um potencial pedagógico que ainda está longe de ser totalmente explorado, seja como fonte de conhecimentos ou instrumento de aprendizagem, seja como espaço de comunicação e interação social. O museu deve, por isso, servir de fonte de formação para as escolas e sociedade geral, por meio da prestação de serviços educativos e do estreitamento de laços institucionais. 
Ao longo dos anos as pesquisas e práticas educacionais e comunicacionais, relacionadas com exposições em museus, intensificaram-se, reforçando o seu papel na produção do conhecimento (VALENTE; CAZELLI; ALVES, 2005). Cada vez mais os museus possibilitam uma intensa interação entre os visitantes e, por esse motivo, são ambientes ricos em experiências que podem proporcionar afetividade ao que está a ser apresentado (QUEIROZ et al., 2011).

Quanto à tecnologia, verifica-se que está cada vez mais presente no cotidiano das pessoas. Esses dados são corroborados por Gomes (2018), ao afirmar que os docentes necessitam buscar metodologias de ensino que estimulem a aprendizagem dos alunos de forma mais dinâmica e estimuladora.

Nos trabalhos de tecnologia analisados verificou-se a preocupação com a formação dos professores nesta área, evidenciada também por Gomes (2018) ao referir que as tecnologias exigem uma mudança de postura dos professores, posto que estes precisam investir na formação continuada para poder manusear os recursos tecnológicos com autonomia e de forma planejada, com objetivos preestabelecidos, para, assim, contribuir, de forma significativa, para o processo de ensino aprendizagem. Perante esta situação, pode-se afirmar que o uso das tecnologias não é um processo fácil. Por um lado ainda existem professores que não se adequaram a essas tecnologias, e, por outro, algumas instituições não oferecem esses recursos tecnológicos para diversificar as práticas docentes, dos mediadores e das atividades, ou, quando oferecem, não apresentam condições de uso.

\section{CONSIDERAÇÕES FINAIS}

Mediante os dados obtidos nesta pesquisa foi possível atingir o objetivo proposto, uma vez que foi observada a inexistência de trabalhos que discutam como a tecnologia tem sido utilizada em espaços não formais de educação, mais especificamente os museus. Isso não quer dizer que não existam em outras revistas da área de ensino, com outros Qualis, em outros idiomas e em um período diferente do analisado.

Outro aspecto importante suscitado com este estudo diz respeito ao número reduzido de artigos publicados, quer na área dos museus, quer na área do uso da tecnologia, apesar de a literatura destacar a importância dos museus como espaços educativos e da necessidade da apropriação da tecnologia para as práticas pedagógicas. Assim, inferimos que são necessários mais investimentos em estudos que problematizem o uso da tecnologia por professores, mediadores e responsáveis por espaços educativos não formais, inovando suas práticas e tornando as atividades mais dinâmicas, estimulantes e motivadoras.

Os espaços não formais, como os museus, precisam manter a sua essência, mas, ao mesmo tempo, necessitam inovar-se com tecnologias para interagir com os visitantes, quer seja de modo presencial, quer seja de forma remota. Além disso, a tecnologia será uma maneira de estes espaços chegarem também até as pessoas que, por vários motivos, podem não se deslocar ao museu de forma física. 
Diante de nossas conclusões, incentivamos que mais estudos sejam desenvolvidos no sentido de entender como os museus de ciências estão utilizando a tecnologia em suas exposições e atividades educativas.

\section{REFERÊNCIAS}

ALBAGLI, S. Divulgação científica: informação científica para a cidadania. Ciência da informação, v. 25, n. 3, p. 396-404, 1996.

BARDIN, L. Análise de conteúdo. São Paulo: Edições 70, 2011.

BASSOLI, F. O processo de apropriação da bioexposição "A célula ao alcance da mão" em um centro de ciências: desafios da mediação. Ensaio: Pesquisa em Educação em Ciências, v. 15, n. 1, p. 155-154, 2013.

CASCAIS, M. G. A.; GHEDIN, E.; TERÁN, A. F. O significado da questão do conhecimento para a alfabetização científica. Revista Areté - Revista Amazônica de Ensino de Ciências, v. 4, n. 7, 2014.

CHELINI, M. E.; LOPES, S. G. B. C. Exposições em museus de ciências: reflexões e critérios para análise. Anais do Museu Paulista: História e Cultura Material, v. 16, n. 2, p. 205-238, 2008.

COSTA, H.; WAZENKESKI, V. A importância das ações educativas nos museus. Ágora - Revista de História e Geografia, v. 17, n. 2, p. 64-73, 2015.

FALK, J. H.; NEEDHAM, M. D. Measuring the impact of a science center on its community. Journal of Research in Science Teaching, v. 48, n. 1, p. 1-12, 2011.

FREITAS, H. M. R.; CUNHA, M. V. M.; MOSCAROLA, J. Aplicação de sistemas de software para auxílio na análise de conteúdo. Revista de Administração da USP, v. 3, n. 32, p. 97-109, 1997.

GALVÃO, M. C. B. O levantamento bibliográfico e a pesquisa científica. 2017. Disponível em: http://www2. eerp.usp.br/Nepien/DisponibilizarArquivos/Levantamento_bibliografico_CristianeGalv.pdf. Acesso em: 16 abr. 2020.

GILBERT, J. K. Educación tecnológica: una nueva asignatura en todo el mundo. Enseñanza de las Ciencias, v. 13, n. 1, p. 15-24, 1995.

GOMES, J. O uso das tecnologias em sala de aula. Revista Partes, v. 1, n. 1, p. 1-17, 2018.

GOUVÊA, G.; VALENTE, M. E.; CAZELLI, S.; MARANDINO, M. Redes cotidianas de conhecimentos e os museus de ciência. Parcerias Estratégicas, v. 6, n. 11, p. 169-174, 2010.

JACOBUCCI, D. F. C. Contribuições dos espaços não formais de educação para a formação da cultura científica. Em Extensão, Uberlândia, v. 7, p. 55-66, 2008.

LOUREIRO, J. M. M. Museu de ciência, divulgação científica e hegemonia. Ciência da Informação, v. 32, n. 1, p. 88-95, 2003.

MACHADO, A.; SILVA, A.; CATAPAN, A. Convergência entre a comunicação digital e a prática da Educação a Distância. Revista E-Tech: Tecnologias para Competividade, v. 7, 4a edição especial, p. 55-70, 2014.

MARANDINO, M. Faz sentido ainda propor a separação entre os termos educação formal, não formal e informal? Revista Ciência \& Educação, v. 23, n. 4, p. 811-816, 2017.

MARANDINO, M. Enfoques de educação e comunicação nas bioexposições de museus de ciências. Revista Brasileira de Pesquisa em Educação em Ciências, v. 3, n. 1, 2011.

MARCONSIN, N. M. A.; OLIVEIRA, G. C. G.; RIBEIRO, F. S. L. Visitas guiadas a um espaço de divulgação científica: avaliação e impacto em uma atividade escolar formal. In: ENCONTRO NACIONAL DE PESQUISA EM EDUCAÇÃO EM CIÊNCIAS (ENPEC), 9., 2013. Águas de Lindóia. Anais [...]. Águas de Lindóia, SP, Brasil, 10 a 13 nov. 2013. V. 14.

OLIVEIRA, S.; SILVA, B. Os museus e a internet: a necessidade de um agir comunicacional. In: Avaliação Online. Minho: Centro de Competência da Universidade do Minho, 2008. p. 199-215.

OLIVEIRA, S.; SILVA, B. O museu e a escolar: que relação? O caso do Museu Agrícola de Entre Douro e Minho. In: CONGRESSO INTERNACIONAL GALEGO-PORTUGUÊS DE PSICOPEDAGOXIA, 9., 2011. Corunha. Actas [...]. Corunha: Universidade da Corunha, 2011. p. 2.460-2.471.

PACKER, J. Beyond learning: Exploring visitors' perceptions of the value and benefits of museum experiences. Curator: The Museum Journal, v. 51, n. 1, p. 33-54, 2008.

PIVELLI, S. R. P. Análise do potencial pedagógico de espaços não-formais de ensino para o desenvolvimento da temática da biodiversidade e sua conservação. 2006. Tese (Doutorado) - Universidade de São Paulo, 2006. 
QUEIROZ, G.; KRAPAS, S.; VALENTE, M.; DAVID, E.; DAMAS, E.; FREIRE, F. Construindo saberes da mediação na educação em museus de ciências: o caso dos mediadores do museu de astronomia e ciências afins/Brasil. Revista Brasileira de Pesquisa em Educação em Ciências, v. 2, n. 2, p. 77-88, 2011.

SILVA, H.; AZEVÊDO, L.; GOMES, A.; MARTINS, C.; MAIA, D. Levantamento bibliográfico da pesquisa científica de jogos digitais voltados para o Ensino e aprendizagem. CEUR-WS.org, v. 2.117, p. 11-20, 2017.

VALENTE, M. E.; CAZELLI, S.; ALVES, F. Museus, ciência e educação: novos desafios. História, Ciências, Saúde, Manguinhos, v. 12, p. 183-203, 2005.

VERASZTO, E.; SILVA, D.; SIMON, F.; BARROS FILHO, J.; BRENELLI, R. Tecnologia no Ensino Fundamental: uma proposta metodológica. In: SIMPÓSIO EM FILOSOFIA E CIÊNCIA, 5., Trabalho e conhecimento: desafios e responsabilidades das ciências. 2003. Marília. Anais eletrônicos [...]. Marília: Unesp Marília Publicações, 2003.

VERASZTO, E.; SILVA, D.; MIRANDA, N.; SIMON, F. Tecnologia: buscando uma definição para o conceito. Prisma.com, n. 7, p. 60-85, 2008. 